\title{
Three-Dimensional Tracking of Juvenile Salmon at a Mid-Reach Location between Two Dams
}

Xinya $\mathrm{Li}^{\mathrm{a}}$, Z. Daniel Deng ${ }^{\mathrm{a},{ }^{*}}$, Jayson J. Martinez ${ }^{\mathrm{a}}$, Tao Fu ${ }^{\mathrm{a}}$, P. Scott Titzler ${ }^{\mathrm{b}}$, James S. Hughes ${ }^{\mathrm{b}}$, Mark A. Weiland ${ }^{\mathrm{b}}$, Richard S. Brown ${ }^{\mathrm{b}}$, Bradly A. Trumbo ${ }^{\mathrm{c}}$, Martin L. Ahmann ${ }^{\mathrm{c}}$, Jon F.

Renholds $^{c}$

${ }^{a}$ Pacific Northwest National Laboratory, Hydrology Group, 3320 Innovation Boulevard, P.O. Box 999, MSIN K9-33, Richland, WA 99352.

${ }^{b}$ Pacific Northwest National Laboratory, Ecology Group, 3320 Innovation Boulevard, P.O. Box 999, MSIN K7-70, Richland, WA 99352.

${ }^{c}$ U.S. Army Corps of Engineers, Walla Walla District, 201 N Third Ave, Walla Walla, WA 99362.

*Corresponding Author. Tel.: +1 509372 6120; Email address: zhiqun.deng@ @nnl.gov 


\begin{abstract}
Evaluating fish behavior and migration in response to environmental changes is a fundamental component of fisheries research and recovery of freshwater ecosystems. While spatial distribution and behavior of fishes has been well studied around hydropower facilities, little research has been conducted at a mid-reach location between two dams. The Juvenile Salmon Acoustic Telemetry System (JSATS) cabled receiver system was developed and employed as a reference sensor network for detecting and tracking juvenile salmon in the Columbia River Basin. To supplement acquisition of detection and three-dimensional (3-D) tracking data to estimate survival and fish behavior in the forebays of Little Goose and Lower Monumental dams on the Snake River in eastern Washington State, a mid-reach location was needed to investigate the spatial distribution of migrating juvenile salmon in open-water conditions between the two dams. Lyons Ferry Bridge on State Route 261 at the confluence of the Snake and Palouse Rivers was chosen as the mid-reach location. A JSATS-cabled receiver system configuration was successfully designed and deployed from the bridge's pier structure. Theoretical analysis confirmed the functionality and precision of the deployment design. Validation tests demonstrated sub-meter accuracy of 3-D tracking up to a horizontal distance of $50 \mathrm{~m}$ upstream and downstream from the Lyons Ferry Bridge piers. Detection and tracking probabilities were on the LFB cabled array were estimated to be $99.98 \%$ from field application. This research provided a detailed description of acoustic telemetry system deployment and 3-D tracking as guidance for better understanding of fish migration behavior as they pass through dams and continue downstream through the river between dams.
\end{abstract}

Keywords: acoustic telemetry; 3-D tracking; juvenile salmon; mid-reach reservoir 


\section{Introduction}

Acoustic telemetry systems have been used for fish tracking to determine movement patterns (e.g., seasonal change, preference of water depth or temperature, etc.), foraging behavior, habitat utilization, spawning behavior, and site fidelity (Metcalfe and Arnold, 1997; Roussel et al., 2000; Meyer et al., 2000; Cooke et al., 2013). High detection rates of signals with individualized frequency and pulse codes can provide detailed information on both obvious and subtle fish behavior (Berman and Quinn, 1991). With recent improvements in the technology, acoustic telemetry has been used to monitor the migration and passage behavior of fish through hydroelectric facilities in rivers (Schilt, 2007). A recent example is the Juvenile Salmon Acoustic Telemetry System (JSATS), which has been used to monitor survival and observe the behavior of juvenile salmonids passing through eight large hydroelectric facilities within the Federal Columbia River Power System enroute to the Pacific Ocean since 2006 (McMichael et al., 2010; Weiland et al., 2011; Deng et al., 2011; Skalski et al., 2014).

Three-dimensional localization solvers (Bucher and Misra, 2002; Li et al., 2014) were used to estimate 3-D positions of fish implanted with acoustic transmitters as they approach and pass the dams. In previous studies using JSATS, these techniques were used with high accuracy and efficiency to examine fish behavior in the forebays of dams and to detail passage route-specific survival rates and near-dam vertical distribution data. Fish behavior in a forebay was analyzed to monitor behavior, milling, and depth distribution during approach because of the possibility of damage to swim bladders (barotrauma) during turbine passage when fish are exposed to rapid decompression (Tsvetkov et al., 1972; Brown et al., 2012). This kind of information is critical for future designs, operations and evaluations of new turbine. To our knowledge, little published 
research has been conducted on the spatial distribution and fish movement behavior continuously at a mid-reach location between two dams.

Fish behavior, especially the vertical distribution of juvenile anadromous fish, in a reservoir environment without the immediate operating influence of existing large hydropower facilities has not been investigated previously using the JSATS-cabled receiver system. Compared to movement behavior in the forebay environment where fish are milling to find a passage route, fish in the reservoir may behave more naturally (i.e., swimming predominately in a neutrally buoyant state to conserve energy). To study fish behavior in a mid-reach environment, a more central location between dams is needed to monitor and provide fine-scale movement tracks of downstream migrating fish, in this case juvenile salmon, and to estimate the depth distribution and acclimation depth of the fish. Under similar environmental conditions, such as diel period and water temperature, this study will serve as a reference to determine if a significant difference exists in fish behavior between the mid-reach and near-dam locations.

This study contributed to the understanding of the depth distribution of juvenile salmonids on their seaward migration. Using acoustic telemetry, accurate 3-D positions of juvenile salmonids at a mid-reach location were obtained. This research described in detail, how a cabled hydrophone array was designed, deployed and evaluated at a mid-reach location on the Snake River in eastern Washington. A brief description was also provided for a field scale application that applying a robust approximate maximum likelihood (AML) solver to obtain 3-D tracking results with high accuracy and efficiency.

\section{Material and methods}

\subsection{Site Description}


The Lyons Ferry Bridge (LFB; Washington State Highway 261) study site is 95 rkm upstream from the confluence of the Columbia and Snake rivers (Fig. 1). The LFB study site is also located in a mid-reach reservoir between Little Goose Dam and Lower Monumental Dam. There are two tributaries that enter the Snake River near the LFB mid-reach study site. The Palouse River enters the Snake River from the north approximately $0.5 \mathrm{~km}$ upstream, and the Tucannon River enters from the south approximately $6 \mathrm{~km}$ upstream of the study site. LFB provided a ridged structure to attach JSATS-cabled hydrophone systems. The location and water depth at the bridge piers also helped create the spatial separation needed between hydrophones to estimate 3-D fish movement and behavior. The water depth at this location ranges from $12 \mathrm{~m}$ (near shore) to $25 \mathrm{~m}$, which is representative of the typical mid-reach depth of this reservoir.

\subsection{Acoustic Telemetry Equipment and Deployment Design}

Fish implanted with JSATS transmitters were detected using JSATS-cabled receivers. A single JSATS-cabled array system typically consisted of up to four cabled hydrophones, a signal conditioning amplifier, a data acquisition computer that contains two digital signal processing cards with field-programmable gate arrays and a global positioning system (GPS) card, a GPS antenna, detection software, and decoding software (Weiland et al., 2011). Acoustic transmissions from JSATS transmitters implanted into fish were also detected and decoded by stationary JSATS autonomous receivers (ARs), which were deployed using methods described by McMichael et al. (2010) and Titzler et al. (2010). Prior to deployment, all hydrophones and receivers were evaluated in an acoustic tank lined with anechoic material at the PNNL BioAcoustics \& Flow Laboratory (Deng et al., 2010). This laboratory is accredited by the American Association for Laboratory Accreditation to ISO/IEC 17025:2005, which is the international standard for calibration and testing laboratories. 
In May 2013, 18 cabled hydrophones were installed on the upstream and downstream sides of five LFB piers (Fig. 2). Shallow and deep hydrophones were deployed from each of the piers (Fig. 3). Hydrophone cables were lowered to the river bottom and then routed either north (from bridge piers 4, 5, and 6) or south (bridge piers 7 and 8) to an equipment trailer. For the deeper north side of the Snake River (piers 5 and 6), the vertical spacing between the shallow and deep hydrophones was approximately $15.7 \mathrm{~m}$ and, on the shallower south side of the river, the vertical spacing was $12.6 \mathrm{~m}$ on pier 7 and $9.3 \mathrm{~m}$ on pier 8 (Fig. 3). Horizontal spacing also varied between hydrophones. The horizontal distance between the north shoreline and pier 4 was 82.4 $\mathrm{m}$, pier 4 and 5 was $51.7 \mathrm{~m}$, pier 5 and pier 6 was $67.1 \mathrm{~m}$, pier 6 and 7 was $158.5 \mathrm{~m}$, pier 7 and 8 was $67.1 \mathrm{~m}$, pier 8 and south shoreline was $134.1 \mathrm{~m}$.

Two AR arrays consisting of three ARs each were deployed downstream of LFB (Fig. 2). The first array was deployed approximately $100 \mathrm{~m}$ downstream of the bridge, and the second array was deployed approximately $150 \mathrm{~m}$ downstream of the bridge. The north/south direction separation between each of the ARs was no more than $100 \mathrm{~m}$. The ARs were used to confirm detections and calculate detection probability of the cabled array at LFB.

\subsection{Acoustic Signal Data Processing and Three-Dimensional Tracking}

Decoded transmissions from acoustic transmitters implanted in juvenile salmonids detected on the LFB JSATS-cabled receiver array were saved in data files and processed to produce a data set of valid unique tag-detection events. Multiple filters were applied to refine the set of decodes by removing false positives. The output of this process was a data set of events that included valid tag decodes for all times and locations where receivers were operating. Each event contains continuous tag transmissions from the same tag, and at least six transmissions are required to form an event. An event includes fields that indicated the unique identification 
number (tag code) of the fish, the first and last detection time for the event, the location of detection, and the number of individual tag transmissions detected within the event.

An AML solver (Li et al., 2014) was used to 3-D track tagged fish as they passed the LFB cabled receiver array. This solver was expanded from the two-dimensional AML method developed by Chan et al. (2006). The AML solver is different from exact solvers, such as the method presented by Spiesberger and Fristrup (1990), in that it was developed based on the maximum-likelihood method and can solve nonlinear localization equations considering the influence from measurement noise. For actual implementation, the measurement error of the time of arrival (TOA) was assumed to be an independent, zero-mean Gaussian random variable for each signal transmission. By using the noise (measurement error) covariance, the AML estimator was considered to be a weighted version of the nonlinear least square method. The inverse of the noise covariance served as the weighting matrix. The distances between array hydrophones and the tag were also considered to improve weighting terms, because the signal-tonoise ratio was directly related to the hydrophone tag distances. Longer distances between a shallow sound source and a receiving hydrophone increased the probability of multipath interference. Therefore, hydrophones closer to a transmitter were assigned higher weights. Because accuracy was our priority, maximum-likelihood methods were optimum in the sense that its estimation performance can asymptotically attain the Cramér-Rao lower bound with the highest accuracy, especially when there were more than four hydrophones detecting the same transmission.

Because of the uncertainties associated with field environments, the AML tracking results could be affected by many factors-hydrophone locations, water temperature, temperature gradients, tag transmission signal-to-noise ratios, tag transmission multipath propagation, etc. 
Some tracked points can have large errors, and some points can even be physically impossible. A swimming speed filter was applied to remove erroneous points. The maximum swimming speed, which was assumed to be nine times the fork length of the implanted fish per second (Puckett and Dill, 1984), was used as the criterion.

\subsection{Theoretical Analysis}

Theoretical analysis was conducted prior to the cabled system deployment to optimize the study design and predict the accuracy of the position estimates. For 3-D tracking, at least four different hydrophones are required to form the nonlinear localization equations. The locational precision of a sound source can be estimated as a function of the errors in the measurements of hydrophone locations, TOA/TDOA (time difference of arrival), and signal propagation velocity (Wahlberg et al., 2001; Ehrenberg and Steig, 2002; Ren et al., 2012).

Errors of TOA and TDOA measurements have complicated sources, depending on multiple factors (Mao et al., 2007). However, with the help of the high accuracy GPS-based TOA estimates within the hydrophone array, the measurement errors of TOA were well controlled and assumed to be zero-mean Gaussian distributed with a standard deviation of $10 \mu \mathrm{s}$. In a homogeneous medium (water), the speed of sound can be accurately estimated from a wellestablished fifth-order polynomial equation dependent on water temperature (Marczak, 1997). A $1^{\circ} \mathrm{C}$ deviation at $13^{\circ} \mathrm{C}$ (average water temperature in May 2013 at $\mathrm{LFB}$ ) was investigated in terms of the position accuracy analysis, corresponding to a $3.7 \mathrm{~m} / \mathrm{s}$ standard deviation in the sound speed errors. The accurate positional information of the hydrophones can be obtained from rigorous field surveys and refined GPS calibrations. The measurement error was assumed to be less than $15 \mathrm{~cm}$ based on the survey equipment used and past experience with these types of surveys. The detection range of receiving hydrophones was estimated to be $200 \mathrm{~m}$. The 
positional accuracy analysis considering all three types of errors were performed through Monte Carlo simulations by averaging 100 realizations.

\subsection{Controlled Field Testing}

To evaluate the performance of the deployed cabled hydrophone array and validate the 3-D tracking results, controlled field testing was designed and performed at LFB using a 2.7-m-long, remotely operated boat. This remote-controlled boat was developed specifically for evaluating the accuracy of 3-D tracking of JSATS-cabled arrays (Deng et al., 2011; Weiland et al., 2011). The boat was powered by two 50-lb thrust electric trolling motors. A 3-m-long steel pipe was mounted to the boat and used for positioning transmitters at a fixed depth below the boat. The locations of the transmitters were obtained using a real-time kinematic-GPS system (Trimble GeoExplorer, Trimble Navigation Ltd., Sunnyvale, California) and a depth sensor (HOBO U20001-03, Onset Computer Corporation, Bourne, Massachusetts), which provided benchmark measurements for comparison with the 3-D tracked locations. Water temperature, which was used to estimate sound speed, was measured as a function of time using the depth sensor.

Four acoustic transmitters were attached to the steel pipe at 1.7, 2.0, 2.3 and $2.6 \mathrm{~m}$ below the water surface. The antenna of the GPS receiver was located $1.0 \mathrm{~m}$ above the water surface. Each transmitter had a unique pulse repetition interval (PRI; i.e. time between successive signal transmissions) value. Transmitter 3, at a depth of $2.3 \mathrm{~m}$, was selected as the primary signal source used for the 3-D accuracy assessments. This transmitter had a 2-s PRI.

Data sets were acquired over a 2-day period during the summer of 2013 (May 29 to May 30), through stationary-position tests at LFB. For the stationary-position tests, the boat was held as stationary as possible for at least 3 min to make sure that a sufficient number of transmissions would occur to provide adequate data sets for statistical analyses. According to the symmetric 
geometry of the cabled array, 17 test locations were selected, spaced along the bridge at horizontal distances of 5,50,100, and $150 \mathrm{~m}$ upstream and downstream of the bridge, respectively (Fig. 4). The x-axis of tracking coordinate system was perpendicular to the bridge starting from the centerline of the bridge with the origin at the center of the bridge. The y-axis was set along the bridge centerline, and the $\mathrm{z}$-axis was vertical, pointing downward from the water surface to river bottom. The accuracy was assessed in terms of the median value and the root mean square (RMS) value (without outliers) of absolute differences between GPS measurements and the locations computed from the 3-D tracking solver. Tracking efficiency was defined as number of estimated locations divided by number of transmissions during a test period.

\subsection{Field Scale Application}

The field scale application was held during the summer of 2013. A total of 5,097 subyearling Chinook salmon implanted with JSATS acoustic transmitters were released upstream of LFB as part of another study (Skalski et al., 2014). The median length of implanted fish for the downstream migrating subyearling Chinook salmon was $108 \mathrm{~mm}$ and the median weight was $12.4 \mathrm{~g}$. The transmitters were $10.79 \mathrm{~mm}$ long, $5.26 \mathrm{~mm}$ wide, $3.65 \mathrm{~mm}$ high, and weighed 0.346 g in air (Advance Telemetry Systems [ATS], tag model SS300 with 348 size battery, Isanti, Minnesota). They had a nominal PRI of $4.2 \mathrm{~s}$ and a nominal tag life of 40 days. Implanted subyearling Chinook salmon were released daily during the summer over a 33-day period (June 3 through July 5) upstream of Lyons Ferry Bridge at two different sites. Release site R1 (Snake River km [SRK] 133) was 38 rkm upstream of LFB and $20 \mathrm{rkm}$ upstream of Little Goose Dam. Site R2 (SRK 112) was $17 \mathrm{rkm}$ upstream of LFB and $1 \mathrm{rkm}$ downstream of Little Goose Dam. When passing the LFB study area on their seaward migration, the released fish were successively 
detected by the AR array upstream of LFB (located at Little Goose Dam tailrace, at the same rkm of release site R2 in Fig. 1), LFB cabled array (indicated by red solid dots in Fig. 2) and the AR array downstream of LFB (indicated by orange triangles in Fig. 2).

\subsection{Detection Probability}

To calculate probability of detection at the LFB cabled array we used detection histories for individual fish at the LFB cabled array (primary array) and AR array downstream of LFB (secondary array). Use 0 as not detected and 1 as detected, the possible detection histories for individual fish are as follows:

- "00": never detected on both arrays

- "10": detected on the upstream (primary) array but not on downstream (secondary) array

- "01": detected on the downstream (secondary) array but not on upstream (primary) array

- "11": detected on both arrays

The probability of detection on the primary array can be estimated independently by making the assumption that fish that survived to the secondary array and were detected there $\left(\mathrm{n}_{01}+\mathrm{n}_{11}\right)$ represent a random sample of all fish from the group that were alive as they passed the primary array. The estimated detection probability is then the proportion of the sample that was detected on the primary array $\left[\mathrm{n}_{11} /\left(\mathrm{n}_{01}+\mathrm{n}_{11}\right)\right]$ (Townsend et al., 2006).

\section{Results and Discussions}

\subsection{Theoretical Analysis}

Error distribution contour maps were computed (Fig. 5), assuming all three sources of measurement errors described in section 2.4. Because of the symmetric design of the cabled array system at LFB, only upstream (right half) location estimation errors were presented. The 
location estimation errors at $2.0 \mathrm{~m}$ below the water surface in Fig. 5 were predicted theoretically by assuming error levels for hydrophone locations, sound speed, and TOAs. From the results, the accuracy of location estimates was dependent on the relative location of the hydrophones and the sound source (tag). In the theoretical analysis, there was a positive correlation between the tracking accuracy and the number of hydrophones within reception range of the tagged fish. In our cases, the geometric design of the cabled array at LFB determined the shape of error distribution.

Four hydrophones were the minimum requirement for tracking the source location of the tagged fish; therefore, most of the source locations could not be tracked when the distance from the hydrophones was beyond $150 \mathrm{~m}$ in the horizontal dimension (termed $\mathrm{x}$ in Fig. 5). All four types (distance, $\mathrm{x}, \mathrm{y}$, and $\mathrm{z}$ ) of errors increased significantly when the horizontal dimension increased. The central area of the array (bridge), was influenced less by tracking errors because it was bounded by hydrophones located along most of the entire width of the bridge. Compared to the $\mathrm{x}$ and $\mathrm{z}$ dimensions, the hydrophones spanned $350 \mathrm{~m}$ along the $\mathrm{y}$ direction, and as a result the y errors were the smallest. Along the bridge, areas closer to the front of the hydrophones had higher accuracy in the $\mathrm{x}$ and $\mathrm{z}$ dimensions, especially than the area between the two middle piers which were $158 \mathrm{~m}$ apart. With the contribution of two shallow hydrophones from the most northern pier, location errors were smaller for the northern part of the array than for the southern part of the array. Distance errors, which were calculated by the direct difference in distance between GPS measurements and tracked locations, increased from sub-meter accuracy at distances less than $100 \mathrm{~m}$ to more than $1 \mathrm{~m}$ accuracy at distances greater than $100 \mathrm{~m}$. For depth (z) errors, the most accurate area was within $50 \mathrm{~m}$ of the hydrophone array.

\subsection{Controlled Field Testing}


The tracking efficiency, the median, and RMS errors of $\mathrm{x}, \mathrm{y}$, and $\mathrm{z}$ components were summarized for the transmitter at $2.3 \mathrm{~m}$ below the water surface (Table 1). From location A to location D (Fig. 4), the average tracking efficiency within $50 \mathrm{~m}$ to the bridge was $87 \%$. The lower tracking efficiencies at location E were possibly due to insufficient hydrophones for 3-D tracking. At location E which was beyond the south boundary of the hydrophone array, tracking accuracy, as predicted by theoretical analysis, was also much lower than locations A-D within a $50 \mathrm{~m}$ distance. At a range of $100 \mathrm{~m}$ to the bridge, average tracking efficiency decreased to $52 \%$ with increased tracking error.

At distances up to $50 \mathrm{~m}$ from the bridge, for locations $\mathrm{A}$ to $\mathrm{D}$, the median errors of the $\mathrm{y}$ component ranged from $0.68 \mathrm{~m}$ to $0.95 \mathrm{~m}$, and the RMS errors of the y-component ranged from $0.76 \mathrm{~m}$ to $1.90 \mathrm{~m}$. The median $\mathrm{x}$ errors ranged from $0.12 \mathrm{~m}$ to $1.50 \mathrm{~m}$, while RMS x errors ranged from $0.79 \mathrm{~m}$ to $1.80 \mathrm{~m}$. Within the range of $50 \mathrm{~m}$ upstream and $50 \mathrm{~m}$ downstream of LFB, the errors of the z-component were narrowly bounded, and most locations (A to D) were found to have sub-meter accuracy for the median tracking depth (Fig. 6). The median $\mathrm{Z}$ errors ranged from $0.05 \mathrm{~m}$ to $2.13 \mathrm{~m}$. The RMS $\mathrm{Z}$ errors fell between $0.19 \mathrm{~m}$ and $2.27 \mathrm{~m}$ for the distance from $50 \mathrm{~m}$ to the bridge. The highest tracking depth errors occurred in the northwest corner of the study area (river thalweg) with a median value just over $2 \mathrm{~m}$. Tracking results at upstream locations had smaller errors with narrower bounds than at downstream locations. The directivity of the acoustic transmitter (beam pattern) may have caused this phenomenon. When fish swam downstream before passing LFB, the transmitter faced the upstream hydrophones (facing upstream) resulting in a stronger signal being transmitted toward the hydrophones. When fish passed downstream of LFB, the transmitter faced the opposite direction from the downstream hydrophones (facing downstream) resulting in a weaker signal being transmitted 
toward the hydrophones. Thus, there was a higher probability that an individual transmission (message) was received by more hydrophones at locations upstream of LFB than downstream. At least four hydrophones are required for 3D localization. Algorithms in the 3D tracking solver utilized can take advantage of an overdetermined system (more than four hydrophones for 3D localization) resulting in better performance.

Overall, tracking errors from the field testing reflect system performance in a real environment (e.g. uncertain noise level, stronger multipath) were larger than theoretical errors which were estimated using laboratory-based assumptions (Fig. 7). However, the scale and trends in the errors along all three dimensions were similar between field and theoretical estimates. The differences in the X errors between these two methods were smaller than $0.99 \mathrm{~m}$ except at the test location D_100m (Fig. 7A), where the theoretical method failed to track X positions due to the assumption that the detection range of receiving hydrophones was constant at $200 \mathrm{~m}$. The theoretical method was able to predict that the X error at the test location E_50m should be larger than the other test points, which was also observed in the tracking errors for the field testing. From both methods, the estimated Y errors were constrained below $1 \mathrm{~m}$ for A-D locations (Fig. 7B), while as predicted by the theoretical method and confirmed by the field testing, the y errors were significantly larger at the two E locations (E_5m and E_50m) when the sound source was out of the boundary of the hydrophone array. The differences of Y errors between these two methods ranged from $0.60 \mathrm{~m}$ to $0.89 \mathrm{~m}$ for A-D locations. $\mathrm{Z}$ errors increased gradually for A-D locations when the sound source moved to the locations further away from the bridge and were smaller than $1 \mathrm{~m}$ from both methods except at D_100m. The differences of $\mathrm{Z}$ errors between these two methods ranged from $0.01 \mathrm{~m}$ to $0.41 \mathrm{~m}$ for A-D locations (Fig. 7C). The estimated $\mathrm{Z}$ errors from field testing were larger than $1 \mathrm{~m}$ at $\mathrm{E}$ locations, which was likely 
due to the limited hydrophone coverage in this area with most transmissions only being received by four hydrophones, the minimum number required for 3D tracking.

\subsection{Field Application}

All 2,099 implanted fish released upstream of LFB and downstream of Little Goose Dam at site R2 were detected by the ARs upstream of LFB. Of these 2,099 implanted fish, 2,042 (97\%) were detected by the cabled system at LFB. All 2,042 detected were 3-D tracked. Of the 2,998 fish released upstream of Little Goose Dam at site R1, 2,451 (82\%) were detected by the ARs upstream of LFB. Of these 2,451 implanted fish, 2,341 (96\%) were detected by the LFB cabled system and all 2,341 detected fish were 3-D tracked. In total, 4,550 implanted fish were detected by the upstream AR array. Of these 4,550 fish, 4,383 (96\%) implanted fish were detected by LFB cabled system with a median number of detections of 2,275 per fish ( by all 18 receivers) and a median number of 305 transmissions per fish. 4,383 (96\%) were 3-D tracked of which the median number of tracked positions was 131 per fish (example of individual track Fig. 8). All fish detected by ARs downstream of the bridge (Fig. 2; secondary array) were detected and tracked by the cabled system (primary array) except one fish. As a result, the detection and tracking probabilities on the LFB cabled array were estimated to be $99.98 \%$.

\section{Conclusions}

In this study, a JSATS cabled acoustic receiver system was successfully designed and deployed at LFB to provide high-resolution 3-D tracking data at a mid-reach location between Little Goose Dam and Lower Monumental Dam on the Snake River in Washington State. Theoretical analysis using Monte Carlo simulation predicted the tracking error distribution and thus confirmed the functionality of the deployment design. Validation of the system from field controlled testing demonstrated highly accurate 3-D tracking up to $50 \mathrm{~m}$ upstream and 
downstream at LFB. In the field scale application during the summer of 2013, detection and tracking probabilities were nearly $100 \%$. Spatial distribution information was successfully acquired at this mid-reach location. The obtained 3-D tracking data advanced our understanding of the behavior of juvenile salmonids on their seaward-migrations. 


\section{Acknowledgements}

This study was funded by the U.S. Army Corps of Engineers (USACE) Walla Walla District and conducted at Pacific Northwest National Laboratory (PNNL), which is operated by Battelle for the U.S. Department of Energy. We greatly appreciate the assistance of USACE staff members including Derek Fryer, Eric Hockersmith, Steve Juhnke, Marvin Shutters, and Tim Wik. We are also grateful to many staff of PNNL, Pacific States Marine Fisheries Commission, and the University of Washington for their technical help and field support. 


\section{References}

Berman, C.H., Quinn, T.P., 1991. Behavioural thermoregulation and homing by spring chinook salmon, Oncorhynchus tshawytscha (Walbaum), in the Yakima River. J. Fish. Biol. 39 (3), 301-312.

Brown, R.S., Pflugrath, B.D., Colotelo, A.H., Brauner, C.J., Carlson, T.J., Deng, Z.D., 2012. Pathways of barotrauma in juvenile salmonids exposed to simulated hydroturbines passage: Boyles Law vs. Henry's Law. Fish. Res. 121-122, 43-50.

Bucher, R., Misra, D., 2002. A synthesizable VHDL model of the exact solution for threedimensional hyperbolic positioning system. VLSI Design 15 (2), 507-520.

Chan, Y-T., Hang, H.Y-C., Ching, P-C., 2006. Exact and Approximate Maximum Likelihood Localization Algorithms. IEEE Trans. Veh. Technol. 55 (1), 10-16.

Cooke, S.J., Midwood, J.D., Thiem, J.D., Klimley, P., Lucas, M.C., Thorstad, E.B., Eiler, J., Holbrook, C., Ebner, B.C., 2013. Tracking animals in freshwater with electronic tags: past, present and future. Anim. Biotelem. 1 (5).

Deng, Z., Weiland, M.A., Carlson, T.J., Eppard, M.B., 2010. Design and Instrumentation of a Measurement and Calibration System for an Acoustic Telemetry System. Sensors 10 (4), 3090-3099.

Deng, Z., Weiland, M.A., Fu, T., Seim, T.A., Lamarche, B.L., Choi, E.Y., Carlson, T.J., Eppard, M.B., 2011. A Cabled Acoustic Telemetry System for Detecting and Tracking Juvenile Salmon: Part 2. Three-Dimensional Tracking and Passage Outcomes. Sensors 11 (6), 56615676.

Ehrenberg, J.E. Steig, T.W., 2002. A method for estimating the "position accuracy" of acoustic fish tags. ICES J. Mar. Sci. 59 (1), 140-149. 
Li, X., Deng, Z., Sun, Y., Martinez, J.J., Fu, T., McMichael, G.A., Carlson, T.J., 2014. A 3D approximate maximum likelihood solver for localization of fish implanted with acoustic transmitters. Sci. Rep. 4, Article number: 7215, doi: 10.1038/srep0721.

Mao, G., Fidan, B., Anderson, B., 2007. Wireless sensor network localization techniques. Comput. Netw. 51 (10), 2529-2553.

Marczak, W., 1997. Water as a standard in the measurements of speed of sound in liquids. J. Acoust. Soc. Am. 102 (5), 2776-2779.

McMichael, G.A., Eppard, M.B., Carlson, T.J., Carter, J.A., Ebberts, B.D., Brown, R.S., Weiland, M.A., Ploskey, G.R., Harnish, R.A., Deng, Z. D., 2010. The Juvenile Salmon Acoustic Telemetry System: A New Tool. Fisheries 35 (1), 9-22.

Metcalfe, J. D., Arnold, G. P., 1997. Tracking fish with electronic tags. Nature 387, 665-666.

Meyer, C.G., Holland, K.N., Wetherbee, B.M., Lowe, C.G., 2000. Movement patterns, habitat utilization, home range size and site fidelity of whitesaddle goatfish, Parupeneus porphyreus, in a marine reserve. Environ. Biol. Fish. 59 (3), 235-242.

Puckett, K.J., Dill, L.M., 1984. Cost of Sustained and Burst Swimming to Juvenile Coho Salmon (Oncorhynchus kisutch). Can. J. Fish. Aquat. Sci. 41 (11), 1546-1551.

Ren, H., Deng, Z.D., Carlson, T.J., Sun, Y., Fu, T., Martinex, J.J., Matzner, S., Myers, J.R., 2012. Localization of Southern Resident killer whales using two star arrays to support marine renewable energy. In Oceans, 2012, pp. 1-7. IEEE, 14-19 Oct. 2012.

Roussel, J-M., Haro, A., Cunjak, R.A., 2000. Field test of a new method for tracking small fishes in shallow rivers using passive integrated transponder (PIT) technology. Can. J. Fish. Aquat. Sci. 57 (7), 1326-1329. 
Schilt, C.R., 2007. Developing fish passage and protection at hydropower dams. Appl. Anim. Behav. Sci. 104 (3), 295-325.

Skalski, J.R., Townsend, R.L., Seaburg, A., McMichael, G.A., Harnish, R.A., Oldenburg, E.W., Ham, K.D., Colotelo, A.H.A., Deters, K.A., Deng, Z., Titzler, P.S., Arntzen, E.V., Vernon, C.R., 2014. BiOp Performance Testing: Passage and Survival of Subyearling Chinook Salmon at Little Goose and Lower Monumental Dams, 2013. PNNL-22706, Pacific Northwest National Laboratory, Richland, WA.

Spiesberger, J.L., Fristrup, K.M., 1990. Passive localization of calling animals and sensing of their acoustic environment using acoustic tomography. Am. Nat. 135, 107-153.

Titzler, P.S., McMichael, G.A., Carter, J.A., 2010. Autonomous Acoustic Receiver Deployment and Mooring Techniques for use in Large Rivers and Estuaries. North Am. J. Fish. Manage. 30 (4), 853-859.

Townsend, R.L., Skalski, J.R., Dillingham, P., Steig, T.W., 2006. Correcting bias in survival estimation resulting from tag failure in acoustic and radiotelemetry studies. J. Agric. Biol. Envir. S. 11 (2), 183-196.

Tsvetkov, V.I., Pavlov, D.S., Nezdoliy, V.K., 1972. Changes of Hydrostatic Pressure Lethal to Young of Some Freshwater Fish. J. Ichthyol. 12 (2), 307-318.

Wahlberg, M., Møhl, B., Madsen, P.T., 2001. Estimating source position accuracy of a largeaperture hydrophone array for bioacoustics. J. Acoust. Soc. Am. 109 (1), 397-406.

Weiland, M.A., Deng, Z., Seim, T.A. Lamarche, B.L. Choi, E.Y. Fu, T., Carlson, T.J., Thronas, A.I., Eppard, M.B., 2011. A Cabled Acoustic Telemetry System for Detecting and Tracking Juvenile Salmon: Part 1. Engineering Design and Instrumentation. Sensors 11 (6), 5645-5660. 
Table 1

Tracking efficiency, median and RMS errors of the acoustic transmitter at $2.3 \mathrm{~m}$ below the water surface at each test location in Fig.4.

\begin{tabular}{|c|c|c|c|c|c|c|c|c|}
\hline $\begin{array}{c}\text { Locatio } \\
\mathbf{n}\end{array}$ & $\begin{array}{l}\text { Horizonta } \\
\text { I Distance } \\
\text { to bridge } \\
\text { (m) }\end{array}$ & $\begin{array}{c}\text { Tracking } \\
\text { Efficienc } \\
\mathbf{y}(\%)\end{array}$ & $\begin{array}{l}\text { Media } \\
\text { n X } \\
\text { Error } \\
\text { (m) }\end{array}$ & $\begin{array}{l}\text { Media } \\
\text { n Y } \\
\text { Error } \\
\text { (m) }\end{array}$ & $\begin{array}{l}\text { Media } \\
\text { n Z } \\
\text { Error } \\
(\mathbf{m})\end{array}$ & $\begin{array}{l}\text { RMS } \\
\text { X } \\
\text { Error } \\
(\mathbf{m})\end{array}$ & $\begin{array}{c}\text { RMS } \\
\text { Y } \\
\text { Error } \\
(\mathbf{m})\end{array}$ & $\begin{array}{c}\text { RMS } \\
\text { Z } \\
\text { Error } \\
\text { (m) }\end{array}$ \\
\hline \multirow{6}{*}{$\mathbf{A}$} & -5 & 100 & 0.12 & 0.75 & 0.44 & 0.81 & 1.09 & 0.64 \\
\hline & 5 & 86 & 1.35 & 0.81 & 0.24 & 1.43 & 0.86 & 0.25 \\
\hline & -50 & 78 & 0.78 & 0.68 & 2.13 & 0.82 & 0.97 & 2.27 \\
\hline & 50 & 78 & 1.29 & 0.75 & 0.41 & 1.41 & 0.85 & 0.40 \\
\hline & -100 & 63 & 0.91 & 0.82 & 3.26 & 1.13 & 0.90 & 3.96 \\
\hline & 100 & 47 & 1.11 & 0.96 & 0.81 & 1.38 & 1.47 & 0.82 \\
\hline \multirow{6}{*}{ B } & -5 & 91 & 1.50 & 0.71 & 1.21 & 1.63 & 0.78 & 1.24 \\
\hline & 5 & 90 & 1.19 & 0.79 & 0.30 & 1.22 & 0.79 & 0.31 \\
\hline & -50 & 88 & 1.19 & 0.74 & 0.43 & 1.24 & 0.76 & 0.79 \\
\hline & 50 & 61 & 1.27 & 0.76 & 0.05 & 1.29 & 0.79 & 0.19 \\
\hline & -100 & 36 & 1.50 & 0.77 & 0.47 & 1.80 & 0.82 & 0.89 \\
\hline & 100 & 41 & 1.28 & 0.80 & 0.65 & 1.36 & 0.83 & 0.73 \\
\hline \multirow{6}{*}{ C } & -5 & 92 & 1.39 & 0.95 & 0.24 & 1.50 & 0.96 & 0.31 \\
\hline & 5 & 75 & 1.20 & 0.92 & 0.38 & 1.51 & 1.54 & 0.45 \\
\hline & -50 & 87 & 1.34 & 0.77 & 0.88 & 1.80 & 1.90 & 1.89 \\
\hline & 50 & 91 & 0.96 & 0.79 & 0.57 & 1.10 & 0.80 & 0.75 \\
\hline & -100 & 69 & 2.15 & 0.91 & 2.91 & 2.91 & 1.53 & 2.86 \\
\hline & 100 & 55 & 1.03 & 0.80 & 0.84 & 1.15 & 0.81 & 1.04 \\
\hline \multirow{6}{*}{ D } & -5 & 88 & 0.76 & 0.88 & 0.45 & 0.79 & 0.92 & 0.43 \\
\hline & 5 & 99 & 0.86 & 0.86 & 0.19 & 0.93 & 0.87 & 0.20 \\
\hline & -50 & 89 & 0.91 & 0.78 & 1.03 & 0.92 & 0.80 & 1.04 \\
\hline & 50 & 95 & 1.29 & 0.90 & 0.57 & 1.34 & 0.90 & 0.65 \\
\hline & -100 & 52 & 1.06 & 0.72 & 1.77 & 1.17 & 0.94 & 1.86 \\
\hline & 100 & 49 & 1.48 & 1.07 & 1.37 & 1.91 & 1.10 & 2.42 \\
\hline \multirow{4}{*}{$\mathbf{E}$} & -5 & 34 & 1.04 & 9.12 & 1.12 & 1.30 & 13.78 & 1.66 \\
\hline & 5 & 74 & 1.23 & 4.02 & 1.39 & 1.44 & 4.70 & 1.56 \\
\hline & -50 & 46 & 0.88 & 2.02 & 1.86 & 1.19 & 2.20 & 1.75 \\
\hline & 50 & 50 & 2.36 & 2.42 & 1.35 & 2.48 & 2.61 & 1.36 \\
\hline
\end{tabular}




\section{Figure Captions}

Fig.1. Locations of three JSATS-cabled hydrophone arrays (Little Goose Dam, Lyons Ferry Bridge, and Lower Monumental) and two release sites (R1 and R2) on the Snake River.

Fig.2. Aerial view of the Lyons Ferry Bridge JSATS study area showing the cabled hydrophone array mounted on the bridge piers (each red dot represents a shallow hydrophone and a deep hydrophone), and autonomous receiver (orange triangle) locations.

Fig.3. Upstream view of the Lyons Ferry Bridge JSATS study area showing bridge array hydrophones and equipment trailer locations. Depths below water surface of shallow and deep pier hydrophones are listed.

Fig.4. Test locations of the remote-controlled boat during field testing at Lyons Ferry Bridge. The letters shown at the right of the figure and the distances on the bottom side are included as location indicators.

Fig.5. Predicted 3-D tracking error distribution upstream of Lyon Ferry Bridge at the shallowhydrophone depth. A) Distance error contour map. B) X error contour map. C) Y error contour map. D) Z (depth) error contour map. White circles along the y-axis represent the locations of hydrophones attached to bridge piers.

Fig.6. Tracking depth errors at the Lyons Ferry Bridge test locations A-E (Fig. 4) of the acoustic transmitter at $2.3 \mathrm{~m}$ below the water surface for horizontal distances of $5 \mathrm{~m}$ and $50 \mathrm{~m}$. A) Downstream locations from the bridge. B) Upstream locations from the bridge.

Fig.7. Comparison of median $\mathrm{x}, \mathrm{y}$ and $\mathrm{z}$ errors estimated from field testing and theoretical analysis at upstream test locations within $100 \mathrm{~m}$.

Fig.8. Example of 3-D tracks at Lyons Ferry Bridge from one tagged fish. A) Aerial view of tracked $\mathrm{x}$ and $\mathrm{y}$ positions. The arrow indicates the flow direction. B) Tracked depth positons by date and time. $\mathrm{z}=0 \mathrm{~m}$ represents the water surface. 


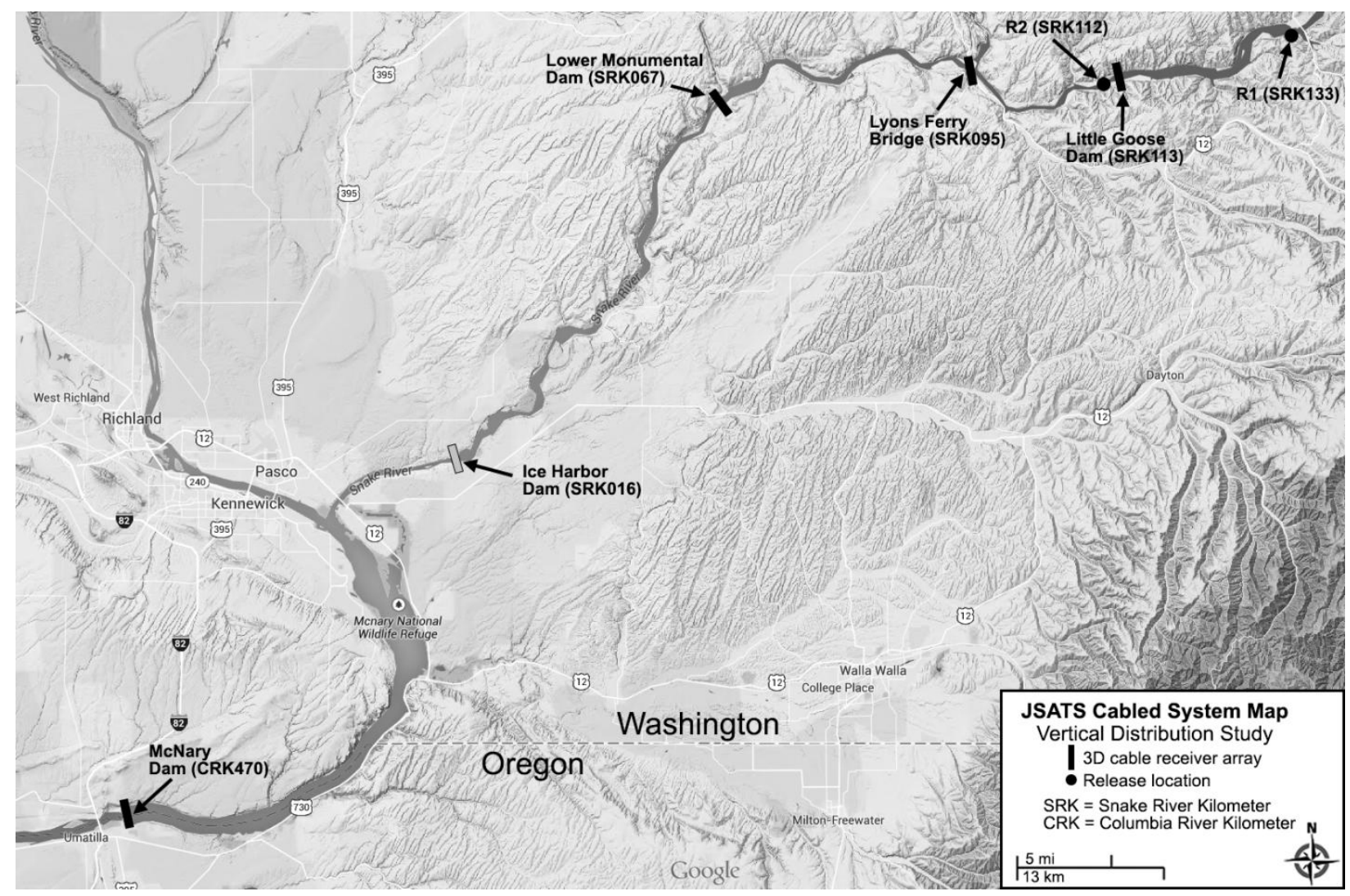

Fig.1. Locations of three JSATS-cabled hydrophone arrays (Little Goose Dam, Lyons Ferry Bridge, and Lower Monumental) and two release sites (R1 and R2) on the Snake River. 


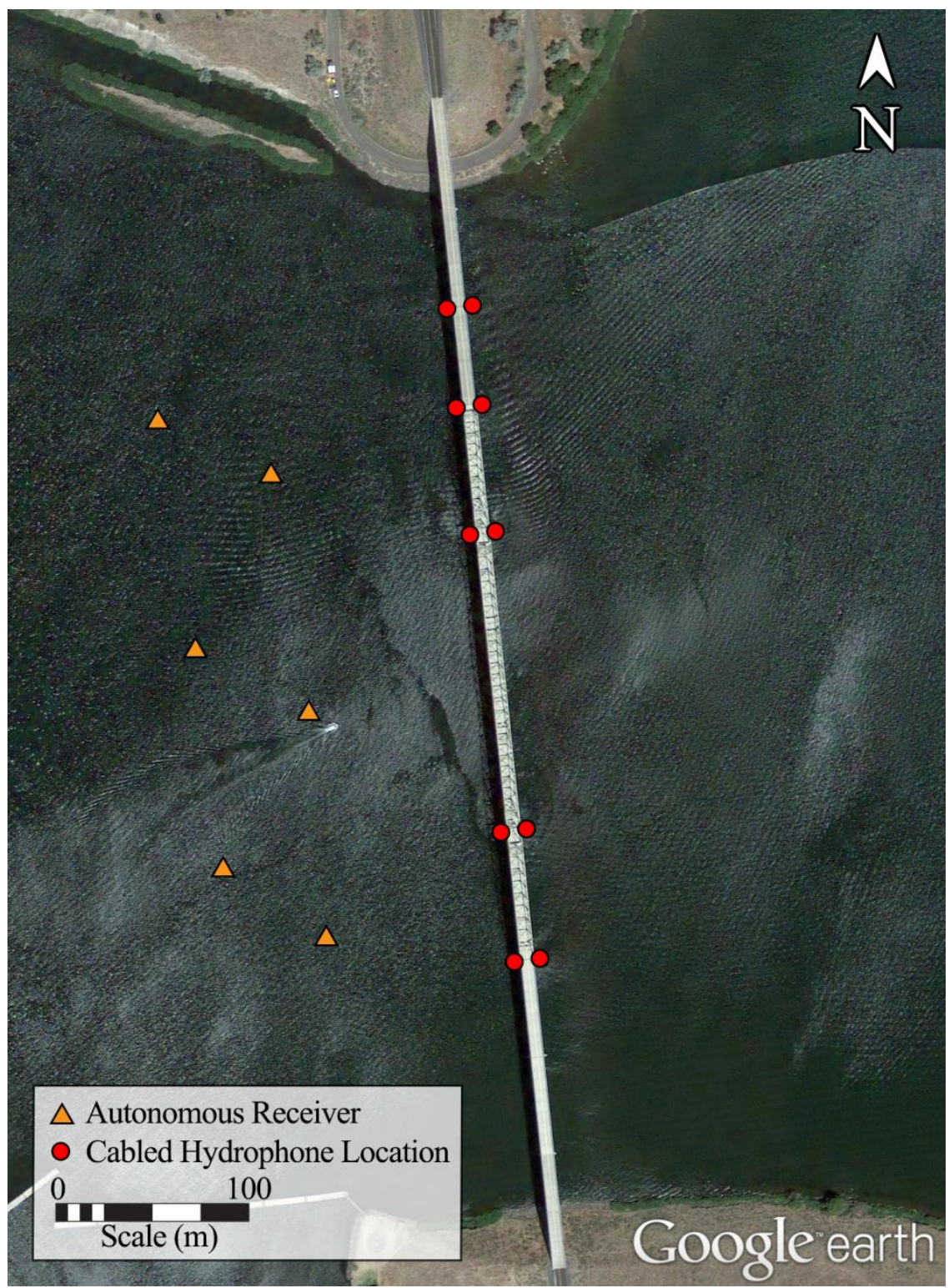

Fig.2. Aerial view of the Lyons Ferry Bridge JSATS study area showing the cabled hydrophone array mounted on the bridge piers (each red dot represents a shallow hydrophone and a deep hydrophone), and autonomous receiver (orange triangle) locations. 


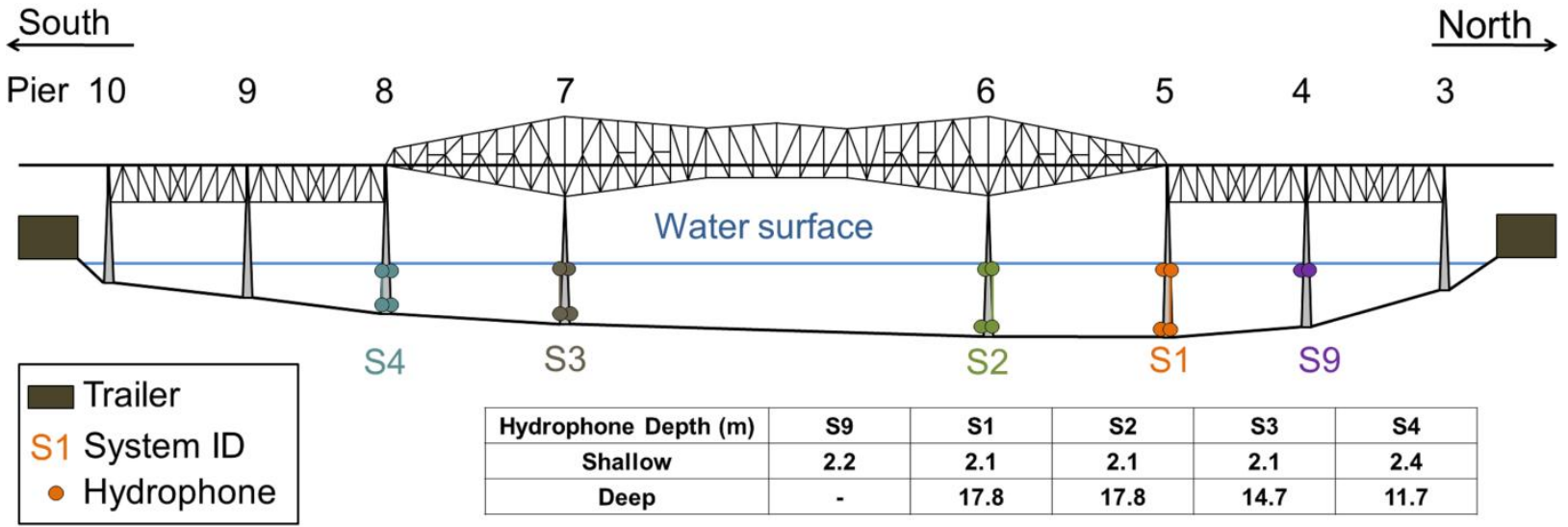

Fig.3. Upstream view of the Lyons Ferry Bridge JSATS study area showing bridge array hydrophones and equipment trailer locations. Depths below water surface of shallow and deep pier hydrophones are listed. 


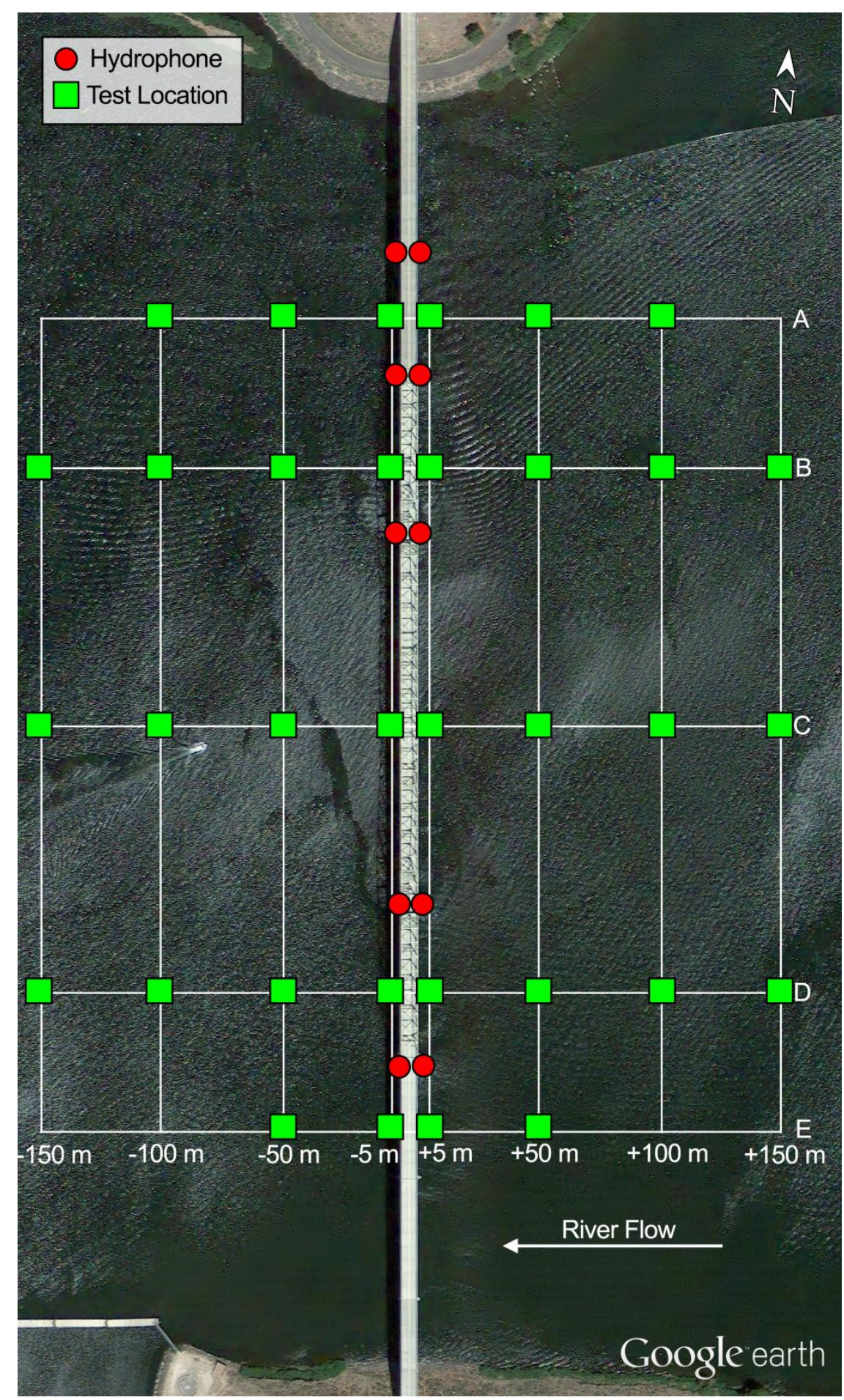

Fig.4. Test locations of the remote-controlled boat during field testing at Lyons Ferry Bridge. The letters shown at the right of the figure and the distances on the bottom side are included as location indicators. 

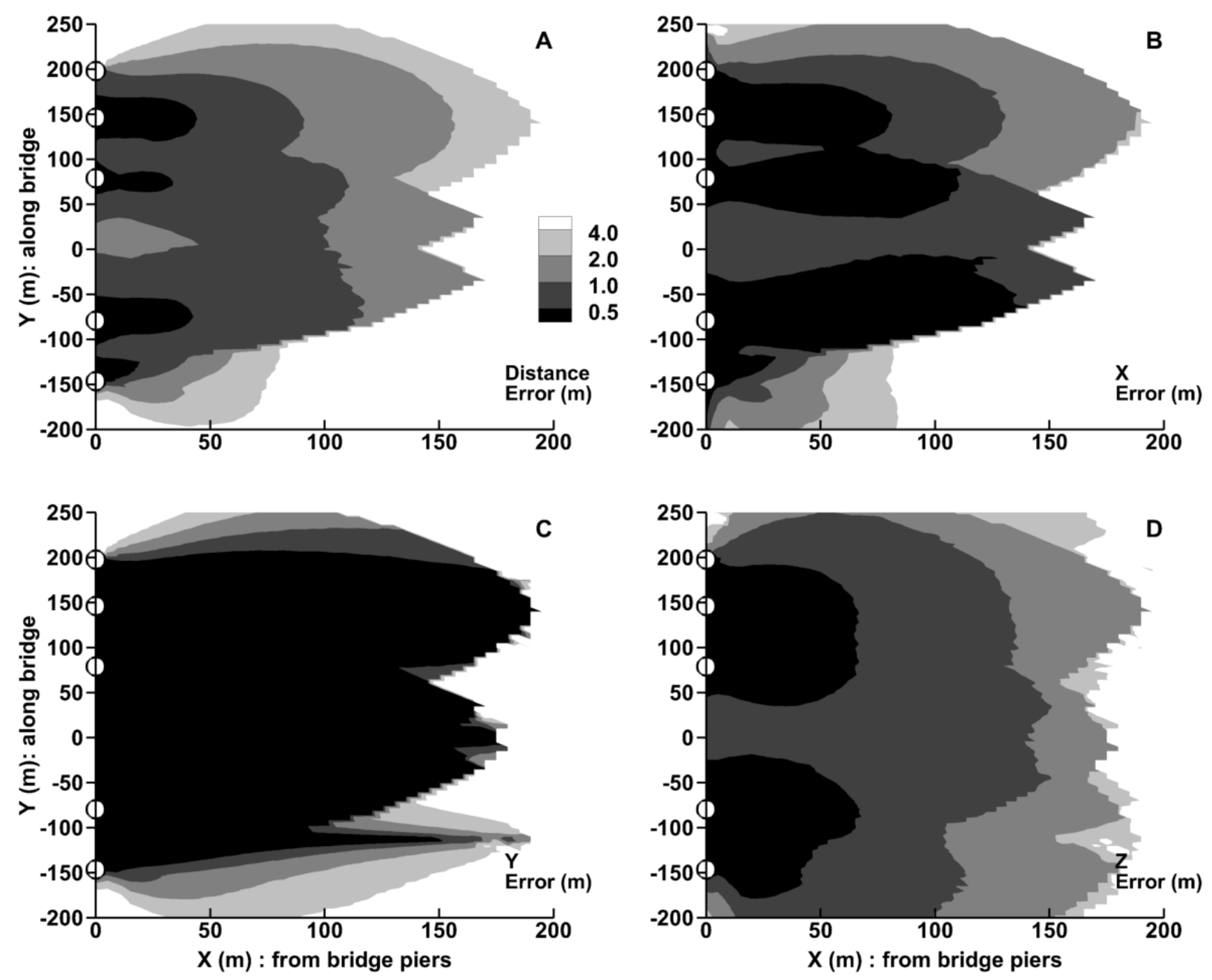

Fig.5. Predicted 3-D tracking error distribution upstream of Lyon Ferry Bridge at the shallow-hydrophone depth. A) Distance error contour map. B) X error contour map. C) Y error contour map. D) Z (depth) error contour map. White circles along the y-axis represent the locations of hydrophones attached to bridge piers. 

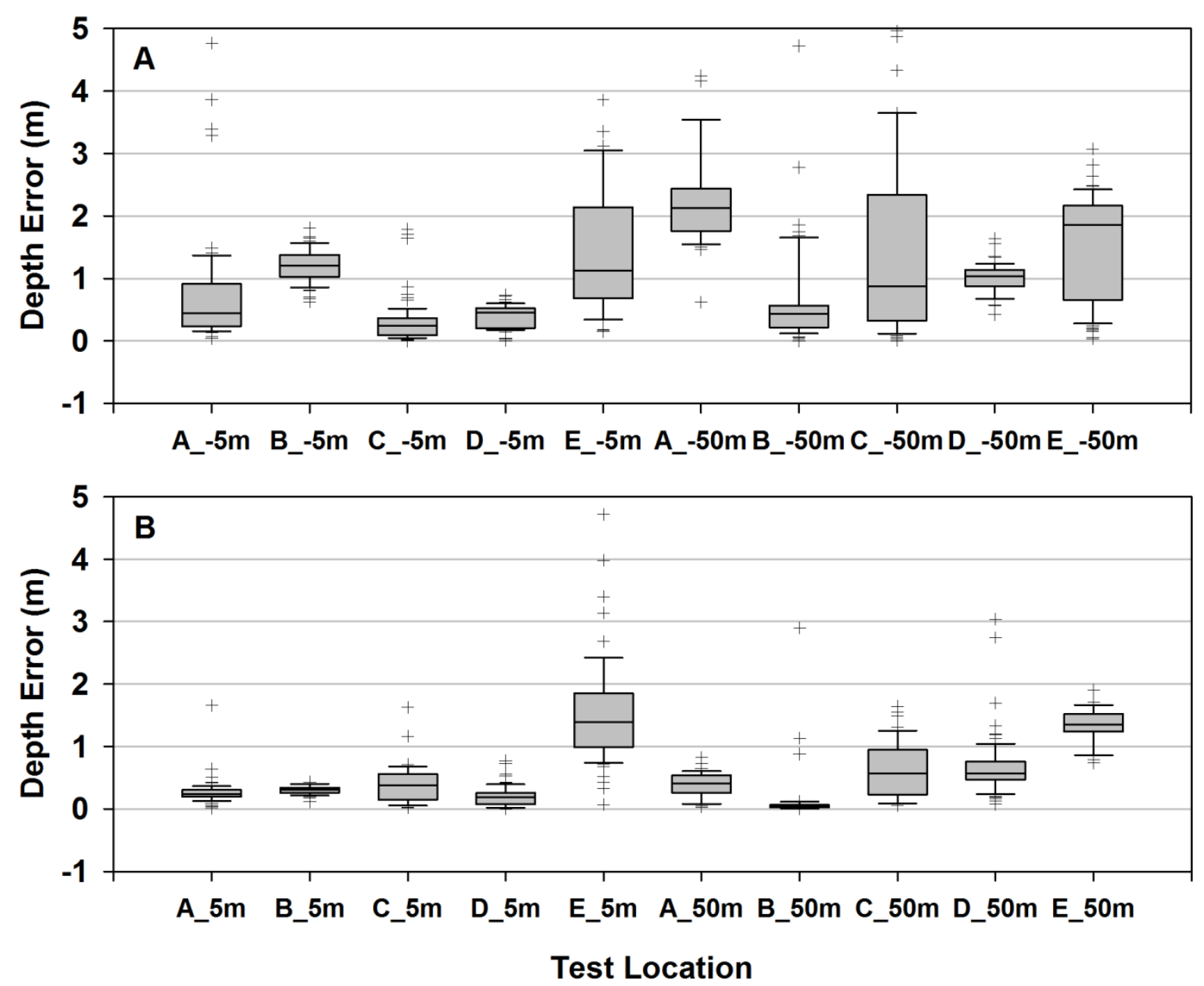

Fig.6. Tracking depth errors at the Lyons Ferry Bridge test locations A-E (Fig. 4) of the acoustic transmitter at $2.3 \mathrm{~m}$ below the water surface for horizontal distances of $5 \mathrm{~m}$ and $50 \mathrm{~m}$. A) Downstream locations from the bridge. B) Upstream locations from the bridge. 

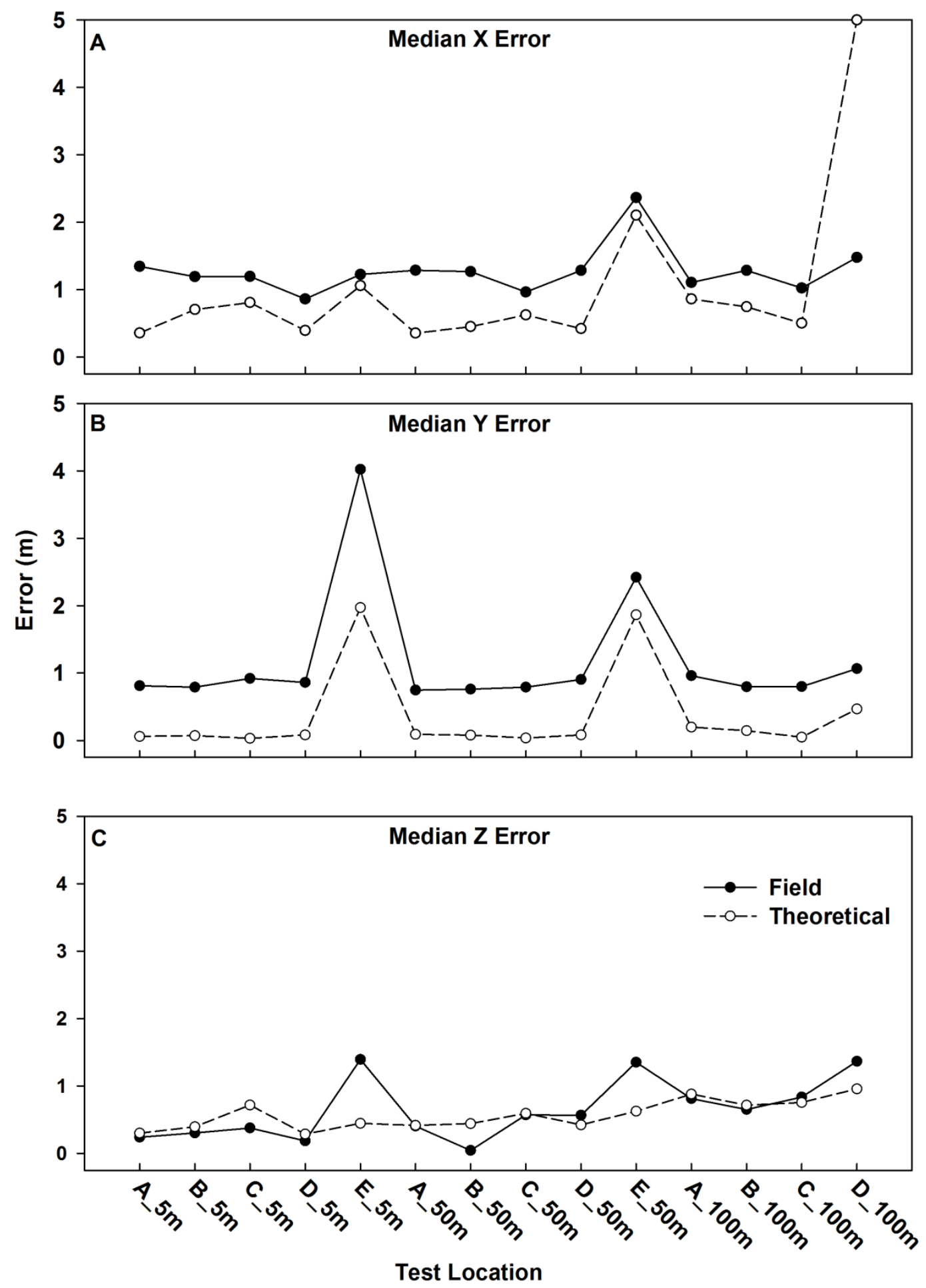

Fig.7. Comparison of median $\mathrm{x}, \mathrm{y}$ and $\mathrm{z}$ errors estimated from field testing and theoretical analysis at upstream test locations within $100 \mathrm{~m}$. 

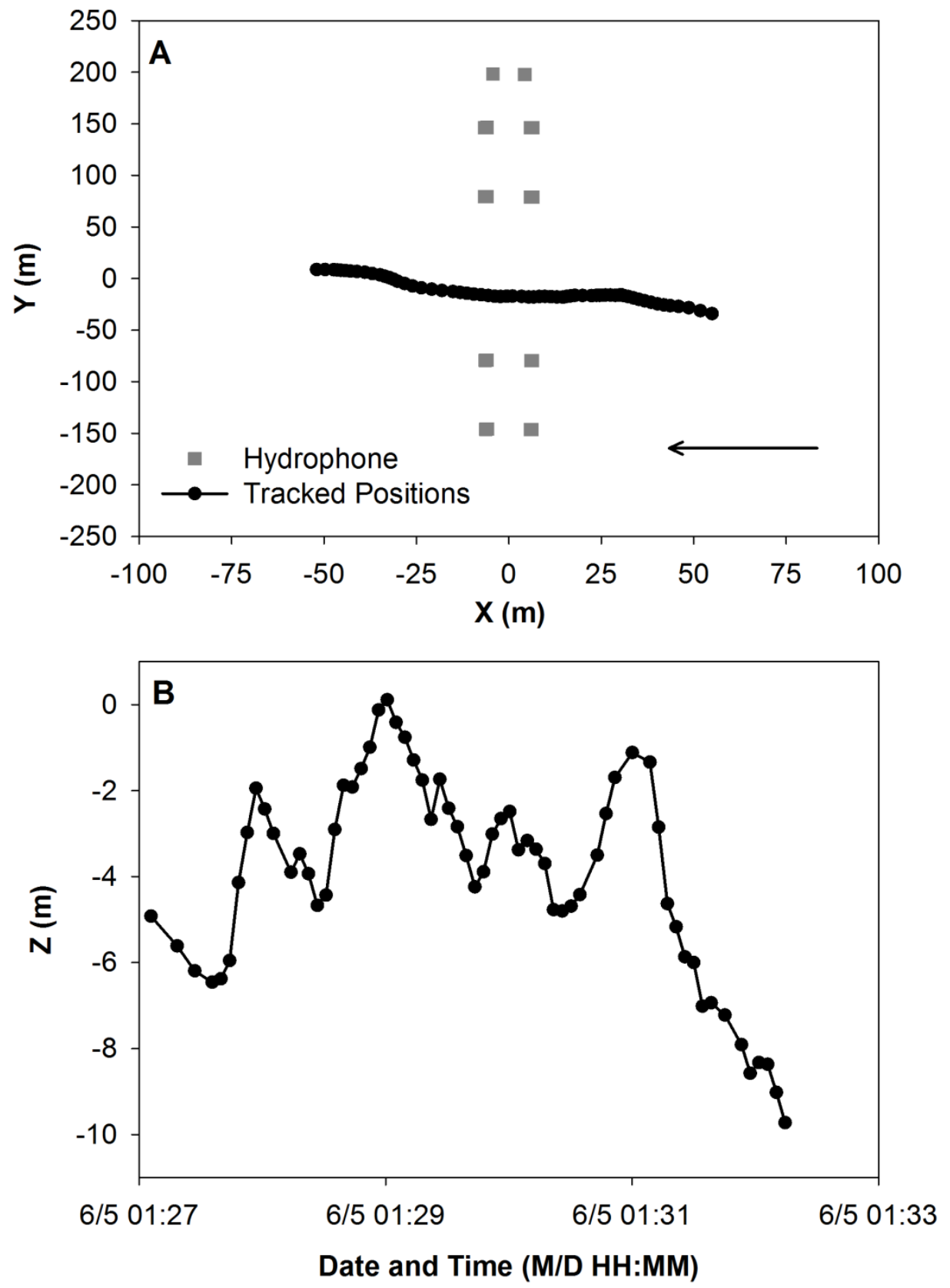

Fig.8. Example of 3-D tracks at Lyons Ferry Bridge from one tagged fish. A) Aerial view of tracked $\mathrm{x}$ and y positions. The arrow indicates the flow direction. B) Tracked depth positons by date and time. $\mathrm{z}=0 \mathrm{~m}$ represents the water surface. 